\title{
Desenvolvimento Sustentável: Uma Análise Contextual do Caso BRICS
}

\section{Sustainable Development: A Contextual Analysis of BRICS' Case}

\section{Desarrollo Sostenible: Un Análisis Contextual del Caso BRICS}

\author{
Aline Pereira Sales Morel \\ Doutoranda em Administração - Programa de Pós-Graduação \\ em Administração (PPGA), Universidade Federal de Lavras \\ Endereço: Rua João Bernardino, 101, Bairro Vila Rica, Lavras- \\ MG. CEP: 37.200-000, Brasil. \\ Telefone: (35) 98839-8780 \\ e-mail: alinepereirasales@gmail.com \\ Patrick Fernandes Lopes \\ Doutorando em Administração - Programa de Pós-Graduação \\ em Administração (PPGA), Universidade Federal de Lavras \\ Endereço: Rua Eduardo Gomes, 83 - Apto. 301 - Vila Murad, \\ Lavras-MG. CEP: 37.200-000, Brasil. \\ Telefone: (35) 99186-727, e-mail: prof.patricklopes@gmail.com
}

\author{
Janderson Martins Vaz \\ Doutorando em Administração - Programa de Pós-Graduação \\ em Administração (PPGA), Universidade Federal de Lavras \\ Endereço: Rua José da Silva Maia, 220, Bairro Jardim Bela \\ Vista, Lavras-MG. CEP: 37.200-000, Brasil. \\ Telefone: (35) 98403-4362, e- \\ mail: janderson.vaz@ifsuldeminas.edu.br
}

\section{Sabrina Soares da Silva}

Professora Adjunta - Programa de Pós-graduação em Administração (PPGA) e Programa de Pós-graduação em Desenvolvimento Sustentável e Extensão (PPGDE) Universidade Federal de Lavras Endereço: Rua Nossa Senhora Aparecida, 96, Centro, CEP: 37.200-000, Lavras, MG, Brasil.

Telefone: (35) 3829-1456, e-mail: sabrinasilva@dae.ufla.br

\section{RESUMO}

Este estudo tem por objetivo fazer uma comparação entre as dimensões econômica, ambiental e social dos membros do BRICS, de forma a oferecer um panorama contextual do desenvolvimento sustentável nesses países. Os dados coletados para realização dessa investigação foram obtidos a partir de indicadores de sustentabilidade mencionados pela literatura consultada e disponibilizados no sítio eletrônico do Banco Mundial, no período compreendido entre 2006 e 2013. Observou-se que, em relação ao desenvolvimento econômico e social, a cooperação entre os países que compõem o BRICS se mostrou eficiente, resultando em avanços nesses aspectos. Já em relação à sustentabilidade ambiental, observou-se que ela não está sendo devidamente contemplada pelos planos de cooperação dos BRICS. Assim sendo, constata-se que, apesar de recente, os BRICS apresentam possibilidades de desenvolvimento sustentável. Entretanto, maior cuidado e esforço deve ser empregado na promoção do desenvolvimento ambiental sustentável desses países emergentes, além de medidas para promover a continuidade dos avanços no desenvolvimento econômico e social.

Palavras-chave: Desenvolvimento Sustentável. BRICS. Análise Contextual.

\section{ABSTRACT}

This study aims to make a comparison between the economic, environmental and social dimensions of the BRICS members in order to provide a contextual perspective of sustainable development in these countries. The data collected for the present investigation were obtained from sustainability indicators mentioned by the literature and available on the website of the World Bank, for the period between 2006 and 2013. It was observed that, in relation to economic and social development,

\footnotetext{
${ }^{1}$ Artigo recebido em 04.02.2015. Revisado pelos pares em 11.09.2015 (blind review). Ajustado e Aceito para publicação em 28.10.2015. Recomendado para publicação por José Ribamar Marques de Carvalho (Editor Científico). Publicado em 05.12.2015. Organização responsável UACC/CCJS/UFCG.
}

REUNIR: Revista de Administração, Contabilidade e Sustentabilidade ISSN: 2237-3667, Vol. 5, n. 3, p.39-58, 2015 
cooperation between the BRICS' countries is efficient, resulting in improvements in these aspects. In relation to environmental sustainability, it was observed that it is not being properly covered by the plans of cooperation of the BRICS. Thus, it appears that, despite recent, the BRICS have sustainable development opportunities. However, extra care and effort must be employed in promoting sustainable environmental development of these emerging countries, as well as measures to promote the continuity of advances in economic and social development.

Keywords: Sustainable Development. BRICS. Contextual Analysis.

\section{RESUMEN}

Este estudio tiene como objetivo hacer una comparación entre las dimensiones económica, ambiental y social de los miembros del BRICS con el fin de proporcionar una perspectiva contextual del desarrollo sostenible en estos países. Los datos recogidos para la presente investigación se obtuvieron de los indicadores de sostenibilidad mencionados en la literatura y en la página web del Banco Mundial para el período entre 2006 y 2013. Se observó que, en relación con el desarrollo económico y social, la cooperación entre los países que integran los BRICS es eficiente, lo que resulta en mejoras en estos aspectos. En relación con la sostenibilidad del medio ambiente, se observó que no se está abordando adecuadamente por los planes de cooperación de los BRICS. Por lo tanto, parece que, a pesar de reciente, los BRICS tienen oportunidades de desarrollo sostenible. Sin embargo, la atención y el esfuerzo extra deben ser empleados en la promoción del desarrollo medioambiental sostenible de estos países emergentes, así como medidas para promover la continuidad de los avances en el desarrollo económico y social.

Palabras clave: Desarrollo Sostenible. BRICS. Análisis Contextual.

\section{INTRODUÇÃO}

Desde o surgimento do homem, há cerca de 100 mil anos, a relação homemnatureza não tem sido muito amistosa. Se em 4 bilhões de anos o planeta não fora agredido, com o início das civilizações, as intervenções humanas começaram a mudar essa história. A situação se agravou ainda mais à medida que a população cresceu e não demonstrou grande preocupação com os impactos ambientais Sabe-se que dos impactos causados, alguns são irreversíveis e outros demandarão grande esforço para serem recuperados (WALLAVER, 2000).

De acordo com dados divulgados pelo Instituto Brasileiro de Geografia e Estatística (IBGE), no ano de 2008 mais de 90\% dos municípios brasileiros, cerca de 5.040 cidades, sofriam algum problema ambiental, sendo os problemas mais comuns: as queimadas, o desmatamento e o assoreamento dos rios. Porém, apenas 18,7\% dos municípios brasileiros possuíam uma estrutura adequada para enfrentar esses desafios ambientais (IBGE, 2008). Além disso, dados da Organização das Nações Unidas (ONU) e do Programa das Nações Unidas para o Desenvolvimento (PNUD) alertam para o consumo de cerca de $40 \%$ acima dos recursos que a Terra é capaz de repor (COZETTI, 2001). A esse respeito, observa-se que os países industrializados detém cerca de $85 \%$ de todo o consumo mundial, ainda que possuam apenas $19 \%$ da população do mundo (VITOR, 2002).

Em face de uma precária perspectiva política e econômica, consolidada na busca incessante pelo crescimento econômico, surgiu uma nova racionalidade, 
defensora da conciliação entre desenvolvimento econômico, preservação ambiental e igualdade social. Essa nova perspectiva, denominada desenvolvimento sustentável, se popularizou a partir da Conferência das Nações Unidas para o Meio Ambiente e Desenvolvimento (CNUMAD).

Nesse cenário de mudanças se insere, ainda, a cooperação internacional para o desenvolvimento, que proporciona a articulação de diversas políticas entre os Estados e organizações privadas em busca de um ideal prioritário: o desenvolvimento solidário (MILANI, 2012). O BRICS, acrônimo correspondente às economias emergentes: Brasil, Rússia, Índia, China e África do Sul, é um acordo de cooperação internacional que surgiu para complementar a governança global em prol da democratização das relações internacionais, do fortalecimento do multilateralismo e da promoção do desenvolvimento (REIS, 2012).

É nesse contexto que se desenvolve esse estudo, que tem por objetivo fazer uma comparação entre as dimensões econômica, ambiental e social dos membros do BRICS, de forma a oferecer um panorama contextual do desenvolvimento sustentável nesses países. Justifica-se, em consonância com Cheng et al. (2007), que o estudo dessas economias se faz relevante, haja vista o impacto sobre a economia global e trajetória, que desafia as principais economias desenvolvidas.

Na próxima seção serão apresentados os fundamentos teóricos que nortearam o desenvolvimento desse estudo. Em seguida, são descritos os procedimentos metodológicos utilizados para consecução do objetivo proposto. Na sequência são apresentados e discutidos os resultados obtidos e, por fim, são feitas as considerações finais do estudo.

\section{REFERENCIAL TEÓRICO}

\subsection{O Desenvolvimento Sustentável versus Indicadores}

A dinâmica de funcionamento da sociedade pós-industrial impôs um estilo de vida insustentável para o meio ambiente, conduzindo a três grandes crises: ecológica, social-econômica e cultural, que estão intimamente interligadas (PEREIRA FILHO \& BAKKER, 2008). O final do século passado presenciou o crescimento da consciência em relação à degradação do meio ambiente e das condições de bem estar social decorrentes do processo de desenvolvimento.

Em 1972, na Conferência de Estocolmo, foram discutidos problemas políticos, sociais e econômicos do meio ambiente global em instância governamental. Buscouse um entendimento sobre as relações entre o ambiente e o desenvolvimento. Surgiu, então, o conceito de eco desenvolvimento, que valoriza o conhecimento das populações locais para a gestão do seu meio. Ignacy Sachs reelaborou esse conceito, 
incluindo a questão da qualidade do crescimento e indicando estratégias de harmonização entre desenvolvimento socioeconômico e gestão ambiental. Sendo assim, o conceito de eco desenvolvimento foi sendo substituído pelo de desenvolvimento sustentável (PEREIRA FILHO \& BAKKER, 2008)

A palavra sustentabilidade vem do latim sustentare que significa suster, suportar, conservar em bom estado, manter, resistir. Sustentável é tudo que é capaz de ser suportado, mantido (CARVALHO, 1993). O termo "desenvolvimento sustentável", que se popularizou a partir da Conferência das Nações Unidas para o Meio Ambiente e Desenvolvimento (CNUMAD) realizada no Rio de Janeiro em 1992, tem na realidade uma longa trajetória (BARBIERI et al., 2010). Para Godard (1997), a expressão remete a uma corrente de reflexões que perdura desde o início da década de 1970.

A Comissão Mundial sobre Meio Ambiente e Desenvolvimento (CMMAD, 1991, p.9), assume o desenvolvimento sustentável como aquele que garante "atender as necessidades do presente sem comprometer a capacidade de as gerações futuras atenderem também às suas". Essa definição abarca alguns elementos importantes, como o reconhecimento de que a sustentabilidade depende do combate à pobreza por meio do desenvolvimento econômico, além de um compromisso intergeracional e o reconhecimento de que o planeta não dispõe de recursos ilimitados para comportar altos padrões de consumo. Esses e outros aspectos têm recebido inúmeras críticas quanto à sua concepção e aplicabilidade (Vizeu, Meneghetti e Seifert, 2012; Barbieri et al., 2010; Drummond, 1999; Baroni, 1992), o que tem dificultado a obtenção de um consenso acerca do conceito. Por outro lado, alguns autores (Diegues, 1992; Batista e Albuquerque, 2007) destacam fatores como o estímulo ao crescimento econômico e superação da pobreza por meio do desenvolvimento como aspectos positivos dessa proposta.

Para Barbieri et al. (2010, p.149), ainda que alvo de tantas críticas, fato é que as propostas referentes ao desenvolvimento sustentável tornaram-se as bases de um dos mais relevantes movimentos sociais contemporâneos. Além disso, que os "valores ligados ao desenvolvimento sustentável e ao respeito às políticas ambientais têm sido institucionalizados em maior ou menor grau nos diversos países pela mídia, pelos movimentos sociais e ambientalistas, e pelos governos".

Com a evolução do conceito de desenvolvimento, passando a incluir dimensões previamente não consideradas, surgiu a necessidade de adaptar os indicadores sociais e econômicos até então utilizados para e orientar o monitoramento e a ação pública e/ou criar novas ferramentas capazes de avaliar todos os elementos constituintes do desenvolvimento sustentável. Os indicadores de sustentabilidade auxiliam os tomadores de decisões a avaliar os resultados práticos das ações para a sustentabilidade. Além disso, eles adicionam as dimensões 
ambiental e cultural aos tradicionais indicadores econômicos e sociais, aumentando a capacidade dos agentes de aferirem a evolução do desenvolvimento (DANIEL, 2000).

A Organização para a Cooperação e Desenvolvimento Econômico (OCDE) adota como princípio que não há apenas um grupo de indicadores, uma vez que os indicadores mais úteis serão sempre em função de seus objetivos (BEZERRA, 2004). O capítulo 40 da Agenda 21, chamado "Informação para a tomada de decisões", consiste em uma compilação de informações que indicam a necessidade da formulação de indicadores globais. A Organização das Nações Unidas (ONU), nesse sentido, tem estimulado os países a estudarem e pesquisarem o uso de indicadores que abordem as dimensões da sustentabilidade.

Sachs (1993 apud PEREIRA FILHO \& BAKKER, 2008), propõe considerar simultaneamente cinco dimensões (ou pilares) para se planejar o desenvolvimento de uma sociedade rumo à sustentabilidade, a saber: social, ecológica, espacial, econômica e cultural. Na questão social, deve-se procurar um desenvolvimento que diminua as diferenças sociais e de distribuição de renda e que aumente a melhoria dos padrões de vida. A sustentabilidade ambiental deve buscar ampliar a capacidade do planeta em fornecer recursos naturais, minimizando os impactos causados. A dimensão econômica deve levar em conta que existem outros aspectos além da manutenção do capital e as transações puramente econômicas. Por fim, a dimensão cultural indica que a população deve ter capacidade e autonomia para elaboração de um projeto de desenvolvimento próprio, integrado e endógeno.

Em resposta aos problemas existentes na agregação de indicadores alguns pesquisadores têm preferido utilizar sistemas ou listas de indicadores que são relacionados a problemas específicos de determinada área investigada (PEREIRA FILHO \& BAKKER, 2008). Para isso, é necessário estabelecer as relações que existem entre as diferentes variáveis que definem os indicadores. Isto só é possível através de mais pesquisas, empíricas e teóricas, que devem auxiliar na compreensão do funcionamento dos complexos sistemas socioecológicos, para que se identifiquem seus mecanismos, atributos e medidas.

Pereira Filho e Bakker (2008) sugerem que sistemas de indicadores de desenvolvimento sustentável devem seguir alguns requisitos universais, os quais são: a) os valores dos indicadores devem ser mensuráveis (ou observáveis); b) deve existir disponibilidade dos dados; c) a metodologia para a coleta e o processamento dos dados, bem como para a construção dos indicadores, deve ser limpa, transparente e padronizada; $d$ ) os meios para construir e monitorar os indicadores devem estar disponíveis, incluindo a capacidade financeira, humana e técnica; e) os indicadores ou grupo de indicadores devem ser financeiramente viáveis; f) deve existir aceitação política dos indicadores no nível adequado, pois, indicadores não legitimados pelos tomadores de decisão são incapazes de influenciar as decisões. 
Outro aspecto importante que deve ser ressaltado é o da participação. A participação constitui elemento fundamental e requerido na utilização de sistemas de indicadores, tanto em termos de políticas públicas como em termos da sociedade civil, reforçando a legitimidade dos próprios sistemas, a construção do conhecimento e a tomada de consciência acerca da responsabilidade ambiental. Nessa mesma linha, Meadows (1998) sugere como características relevantes aos indicadores: a acessibilidade dos dados, clareza na comunicação, relevância, amplitude geográfica, padronização, predição, pró-atividade, sensibilidade temporal, definição de metas, confiabilidade da fonte, capacidade de síntese, capacidade de mensuração, consistência e hierarquia.

Há diversos sistemas de avaliação do desenvolvimento sustentável, todos possuem suas limitações e potencialidades. Entretanto, o conjunto deles oferece importantes subsídios para a elaboração e acompanhamento de políticas públicas. (PEREIRA FILHO \& BAKKER, 2008). As batalhas constantes para diligência e atenção às questões sociais e ambientais exigiram um novo comportamento de países, a fim de garantir a sustentabilidade (SANTANA et al., 2014). Os acordos de cooperação internacional representam importantes iniciativas em prol do desenvolvimento solidário, conforme será demonstrado na seção a seguir.

\subsection{Acordos de Cooperação Internacional para o Desenvolvimento: $O$ Caso BRICS}

Visando um maior desenvolvimento de algum setor específico, ou o crescimento em termos genéricos, os governos dos países valem-se de acordos de cooperação internacional para o alcance desses objetivos. A cooperação internacional para o desenvolvimento pode ser entendida como uma articulação sistemática de diversas políticas entre os estados e organizações privadas, gerando, dessa forma, instituições formais e informais que estabelecem como ideal prioritário o desenvolvimento solidário (MILANI, 2012).

Nesse tipo de relação entre nações existem diversos atores envolvidos e, como em qualquer relação de troca, um desses atores será responsável por ceder, ou doar, enquanto que outro ator será beneficiado. Durante boa parte do período de desenvolvimento do capitalismo, o modelo de cooperação internacional estava pautado na visão desenvolvimentista dos países do Norte, no qual esses seriam os atores "doadores". Contudo, Ullrich e Carrion (2014) ressaltam que os países que surgiram como novas potências emergentes, passando a possuir determinado nível de poder econômico, almejaram maior representatividade e poder político. Dessa forma, ficou estabelecido um novo modelo de cooperação internacional entendido como sendo baseado em relações mais igualitárias solidárias em que predominavam os países do Sul.

REUNIR: Revista de Administração, Contabilidade e Sustentabilidade ISSN: 2237-3667, Vol. 5, n. 3, p.39-58, 2015 
No bojo dessa relação de cooperação internacional para o desenvolvimento dos países do Sul encontra-se a formação do BRICS como um agrupamento informal, mas que na visão de Gonçalves (2011) é a representação de uma nova ordem mundial. O acrônimo BRIC foi concebido em 2001 pelo economista Jim O'Neill, do banco de investimentos Goldman Sachs, para designar o grupo de países composto pelo Brasil, Rússia, Índia e China, que representavam economias emergentes e de relevância crescente na economia mundial. Nesse momento, o Produto Interno Bruto (PIB) desses países representavam, em conjunto, apenas 15\% do PIB das seis maiores economias industriais avançadas (Estados Unidos, Japão, Alemanha, Grã-Bretanha, França e Itália). Mas, a previsão feita por economistas era de uma equiparação nesses números em menos de 40 anos. Desde então, o BRIC despertou a atenção e ganhou destaque no cenário mundial (REIS, 2012; ARMIJO, 2007).

A formação desse acordo remete às transformações vivenciadas no início da década de 1990, que começa com a esperança de que, com o término do conflito ideológico, a globalização iria distribuir mundialmente resultados positivos e que princípios multilaterais passariam a reger a ordem internacional. Mas, em pouco tempo, já se verificava que esse ideal não se concretizou, assim também como uma ordem unilateral, liderada pelos EUA, também não aconteceu, deixando obscura a direção para onde caminhava a ordem internacional. Nesse momento, dificilmente se conceberia a formação de um acordo como o BRICS, haja vista as dificuldades políticas e econômicas vivenciadas por esses países internamente e a hegemonia do G7 (grupo formado pelos países Canadá, França, Itália, Alemanha, EUA, Japão e Reino Unido) (REIS, 2012; FONSECA JR., 2012).

A mudança no cenário político e econômico ocorrida a partir de então contribuiu para o surgimento de novas possibilidades. A tese inicialmente postulada era de que China e Índia se tornariam fornecedores mundiais dominantes de bens manufaturados e serviços e que Brasil e Rússia se tornaram fornecedores dominantes de matérias-primas (CHENG et al., 2007; DOLGIKH \& KOKIN, 2009). A China, nesse momento, tornou-se a segunda maior economia do mundo e a maior exportadora global; o Brasil ascendeu à posição de sexta economia do mundo; a Índia se destacou pelas elevadas taxas de crescimento anual, sendo a nona maior economia do planeta; a Rússia restaurou sua estabilidade econômica, alcançando a posição de décima primeira maior economia mundial; e a África do Sul, com o fim do Apartheid, reconstruiu sua dignidade e fortaleceu sua democracia e economia (REIS, 2012).

Assim, tornou-se explícita a falta de legitimidade das instituições internacionais que emergiram no pós guerra, o que abriu espaço para o surgimento de articulações entre países em desenvolvimento. É nesse contexto que se insere, em 2003, o fórum Índia-Brasil-África do Sul (IBAS) e as Cúpulas bi-regionais ASA (América do Sul-África) e ASPA (América do Sul-Países Árabes) e, posteriormente, o 
BRIC. Esse último acordo surgiu para complementar a governança global, em prol da democratização das relações internacionais, do fortalecimento do multilateralismo e da promoção do desenvolvimento (REIS, 2012). Assim, se separadamente esses países já exerciam alguma influência, juntos, passaram a ter um poder ainda maior de influência (FONSECA JR., 2012).

Do primeiro almoço de trabalho em 2006, à margem da Assembleia Geral das Nações Unidas (AGNU) sob a coordenação russa, passando em 2007 para a coordenação brasileira, a primeira reunião formal de chanceleres realizou-se no ano seguinte em Ecaterimburgo, marcando a instituição do BRIC. Desde então, o termo deixou ser um acrônimo utilizado para identificar os quatro países ascendentes na ordem econômica internacional para se tornar uma entidade político-diplomática. Com a incorporação da África do Sul durante a reunião de chanceleres do BRIC em 2010 e, posteriormente, com a formalização desse novo membro na 3a Cúpula do Agrupamento na China em 2011, o acrônimo foi modificado para BRICS (REIS, 2012).

\begin{abstract}
Atualmente, os países dos BRICS representam 43,03\% da população mundial, $18 \%$ do Produto Interno Bruto (PIB) nominal mundial (25\% do PIB per capita), $25,91 \%$ da área terrestre do planeta e $46,3 \%$ do crescimento econômico global de 2000 a 2008. Ademais, de acordo com a previsão divulgada pelo FMI em 24 de janeiro de 2012, os países do grupo deverão contribuir com 56\% do crescimento do PIB mundial em 2012. A contribuição do G7 para o crescimento da economia mundial será de $9 \%$, menor que a da América Latina (9,5\%). (REIS, 2012, p.34).
\end{abstract}

Os BRICS são hoje mais relevantes para a economia global do que eram na última década. Cada um desses países são importantes por motivos próprios, mas não é possível conceber que algum regime internacional (em áreas como segurança, economia ou valores), se articule ou consolide sem a participação ativa deles (FONSECA JR., 2012). Cheng et al. (2007) acrescenta que as contribuições desse grupo para os mercados globalizados tem sido crescente, fazendo com que seu papel na economia mundial não possa ser desconsiderada.

De acordo com Fonseca Jr. (2012), os BRICS contam com uma dimensão hacia adentro, que abarca atividades de cooperação em áreas como saúde, energia e temas judiciais, e uma dimensão hacia afuera, que busca coordenar o grupo na realização de propostas e reivindicações, buscando influenciar decisões de organismos multilaterais, especialmente na área financeira.

Para Reis (2012) os poucos anos desde a formação do BRIC (agora BRICS) já indicam seu poder de influência sobre a governança global. Economicamente, essa união favoreceu (ainda que parcialmente) a distribuição mais justa do peso econômico dos membros de instituições financeiras internacionais, além de favorecer 
os interesses de outros países em desenvolvimento. Politicamente, notam-se avanços no diálogo e reparação de temas de interesse comum, como a reforma das Nações Unidas e de seu Conselho de Segurança, combate ao terrorismo internacional, desenvolvimento sustentável, erradicação da pobreza, mudança climática e cumprimento das Metas de Desenvolvimento do Milênio, entre outras questões. Além disso, para a autora, os BRICS também conquistaram sua própria agenda de cooperação, obtiveram maior conhecimento entre as sociedades dos cinco países, avançaram na busca formas inovadoras de incentivo ao comércio e investimentos e na cooperação em áreas como agricultura, saúde, ciência e tecnologia.

Fonseca Jr. (2012) esclarece que questionamentos sobre papel futuro dos BRICS sejam naturais e frequentes. Segundo o autor, por esse motivo foi criado no Brasil o BRICS Policy Center. Ele ainda ressalta que a resposta para essa questão não é fácil ou óbvia, podendo variar desde a negação da importância do grupo (embora se reconheça a importância individual de seus membros) até a aceitação de uma nova ordem multipolar que, em parte, culminaria na sua ascensão. Dessa forma, perspectivas contrárias buscariam acentuar as diferenças entre os membros do BRICS ao passo que perspectivas favoráveis ressaltariam as semelhanças.

Cheng et al. (2007) sugerem ser imprescindível para evolução desse grupo a melhoria nas condições de longo prazo e promoção do crescimento, o que implica em estabilidade macroeconômica, o desenvolvimento institucional, político, do comércio e da abertura de investimentos e educação. Nesse sentido, os BRICS ainda precisariam desenvolver muitas etapas para promover essas condições, embora a importância dos primeiros passos dados pelo grupo não possa ser desconsiderada.

\section{PROCEDIMENTOS METODOLÓGICOS}

Essa pesquisa, no tocante aos objetivos, é classificada como descritiva. Segundo Gil (2008, p. 28), "As pesquisas deste tipo têm como objetivo primordial a descrição das características de determinada população ou fenômeno ou o estabelecimento de relações entre variáveis".

Em relação aos procedimentos adotados, a pesquisa se caracteriza como um estudo contextualista. A análise contextualista baseia-se em fenômenos em níveis verticais e horizontais de análise, e as interconexões entre esses níveis através do tempo (PETTIGREW, s/d).

A análise contextualista pode contribuir para uma compreensão holística do processo de formação dos BRICS e suas implicações nos aspectos referentes à sustentabilidade dos países que formam o bloco econômico. Assim sendo, esta pesquisa proporciona, em nível horizontal, uma análise do passado, do presente e do futuro dos BRICS, considerando-se seus indicadores de sustentabilidade. Dessa 
forma, será possível evidenciar possíveis ligações entre o desenvolvimento dos indicadores de sustentabilidade dos países pertencentes a esse bloco econômico. Em nível vertical, a pesquisa realiza uma análise em profundidade dos indicadores de sustentabilidade dos BRICS, proporcionando um novo olhar sobre os indicadores utilizados por outros autores e apresentados no referencial teórico deste estudo.

Os dados coletados para realização dessa investigação são de natureza qualitativa e foram obtidos a partir de indicadores de sustentabilidade mencionados pela literatura consultada e disponibilizados no sítio eletrônico do Banco Mundial.

A seleção dos indicadores a serem utilizados no presente estudo foi feita de forma que pudessem refletir e estabelecer comparações entre as dimensões econômica, ambiental e social dos membros do BRICS e, assim, oferecer um panorama contextual do desenvolvimento sustentável nesses países. A disponibilidade de dados no sítio eletrônico do Banco Mundial também foi um fator que influenciou na escolha dos indicadores.

Assim sendo, foram analisados os dados referentes ao Produto Interno Bruto (PIB), como medida de desenvolvimento econômico, conforme Shi, Hutchinson e Xu (2004) e Santana et al (2014). Como medida de desenvolvimento social foram considerados e analisados os indicadores de "expectativa de vida ao nascer", conforme também foi analisado por Santana et a. (2014) e Lee e Huang (2007). Por fim, como medida de desenvolvimento ambiental foram considerados os indicadores de nível de emissão de CO2, conforme Santana et a. (2014) e Lee e Huang (2007).

Os dados analisados referem-se ao período compreendido entre os anos de 2006 e 2013. O ano de 2006 foi definido como ponto de partida da análise por ser considerado o primeiro ano de efetivação da formalização dos acordos de cooperação entre os países do BRICS. A definição do encerramento da série no ano de 2013 devese à disponibilidade dos dados no sítio eletrônico do Banco Mundial. Para as medidas de expectativa de vida ao nascer, o Banco Mundial disponibiliza os dados até o ano de 2012. Dessa forma, para essas variáveis a série analisada remete ao período de 2006 a 2012.

\section{APRESENTAÇÃO E DISCUSSÃO DOS RESULTADOS}

A análise dos dados referentes aos cinco países que compõem o BRICS foi realizada por meio dos gráficos que serão apresentados a seguir.

\subsection{Desenvolvimento Econômico do BRICS}

No gráfico 1 podem ser visualizados os valores do PIB de Brasil, China, Índia, Rússia e África do Sul no período de 2006 a 2013. 


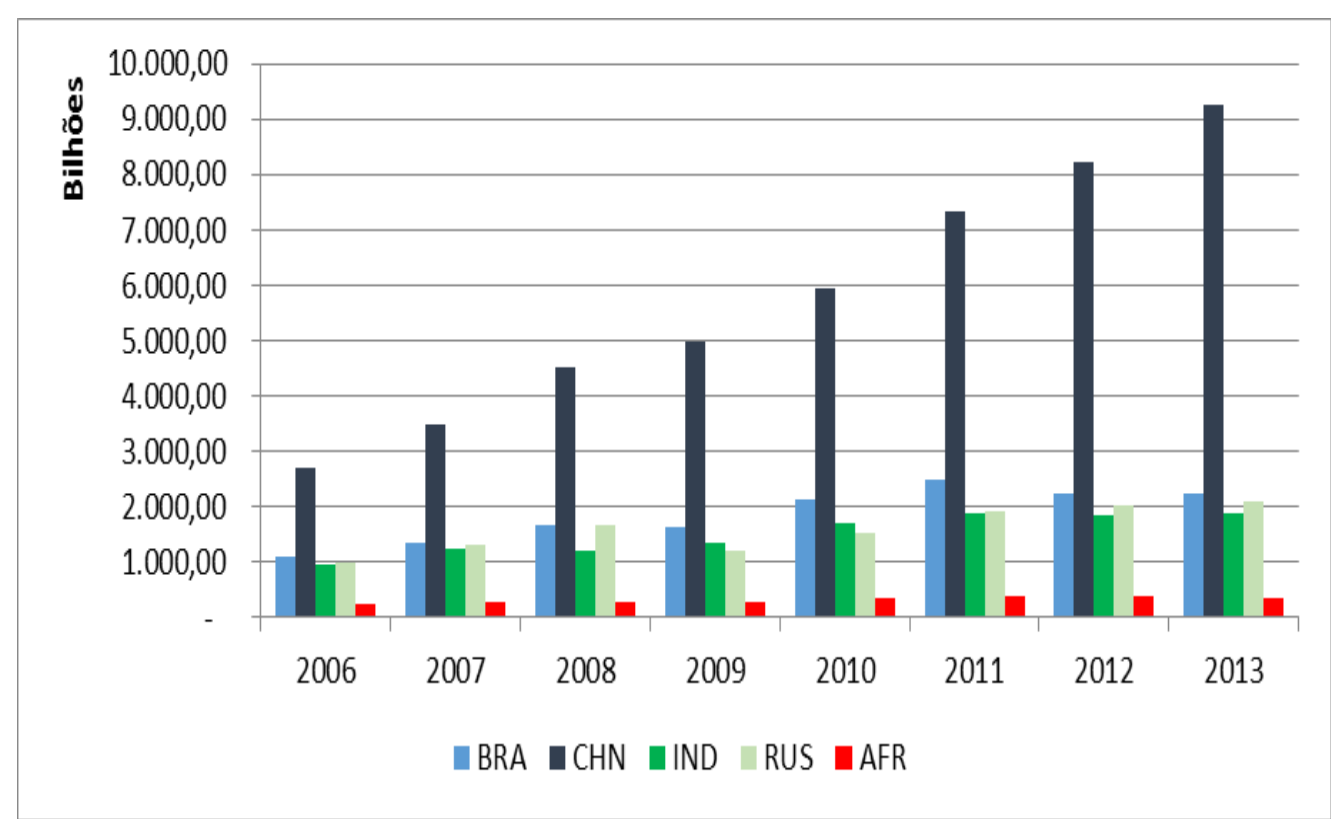

Gráfico 1: Valor do PIB dos países que compõem os BRICS - 2006 a 2013 - em Bilhões de Dólares Fonte: dados da pesquisa

A partir da análise do gráfico percebe-se que o PIB da China sobressai de forma bastante significativa em relação aos demais BRICS. Assim, verifica-se que o período em que o país passou a integrar os BRICS foi benéfico para a sua produção, chegando a atingir um PIB na casa dos nove trilhões de dólares em 2013.

Dessa forma, entende-se que a integração ao BRICS pode ter promovido a sustentabilidade no âmbito econômico para a China, permitindo ao país ter acesso a importantes parceiros comerciais, assim como a potenciais vias de escoamento de produção.

Com relação ao Brasil, os dados apresentados demonstram que a partir dos anos 2010 houve aumento do valor do PIB, chegando o valor dessa variável a representar o dobro da década anterior. Esse mesmo resultado pode ser observado nos casos da Índia e da Rússia.

Contudo, é possível verificar que a África do Sul não apresentou a mesma evolução no PIB, se comparada aos demais BRICS. Assim sendo, entende-se que, com relação ao primeiro aspecto do tripé da sustentabilidade analisado nesse estudo, a integração aos demais BRICS ainda não significou avanços para o país. Cabe ressaltar que a África do Sul começou a fazer parte dos BRICS a partir do ano de 2011. Portanto, existe a necessidade de um acompanhamento desses dados na sequência da década de 2010 para melhor avaliação do caso da África do Sul. 
A oscilação do valor do PIB da África do Sul, bem como dos demais BRICS, pode ser observada no gráfico 2 , que apresenta a taxa de crescimento do PIB anual na série analisada.

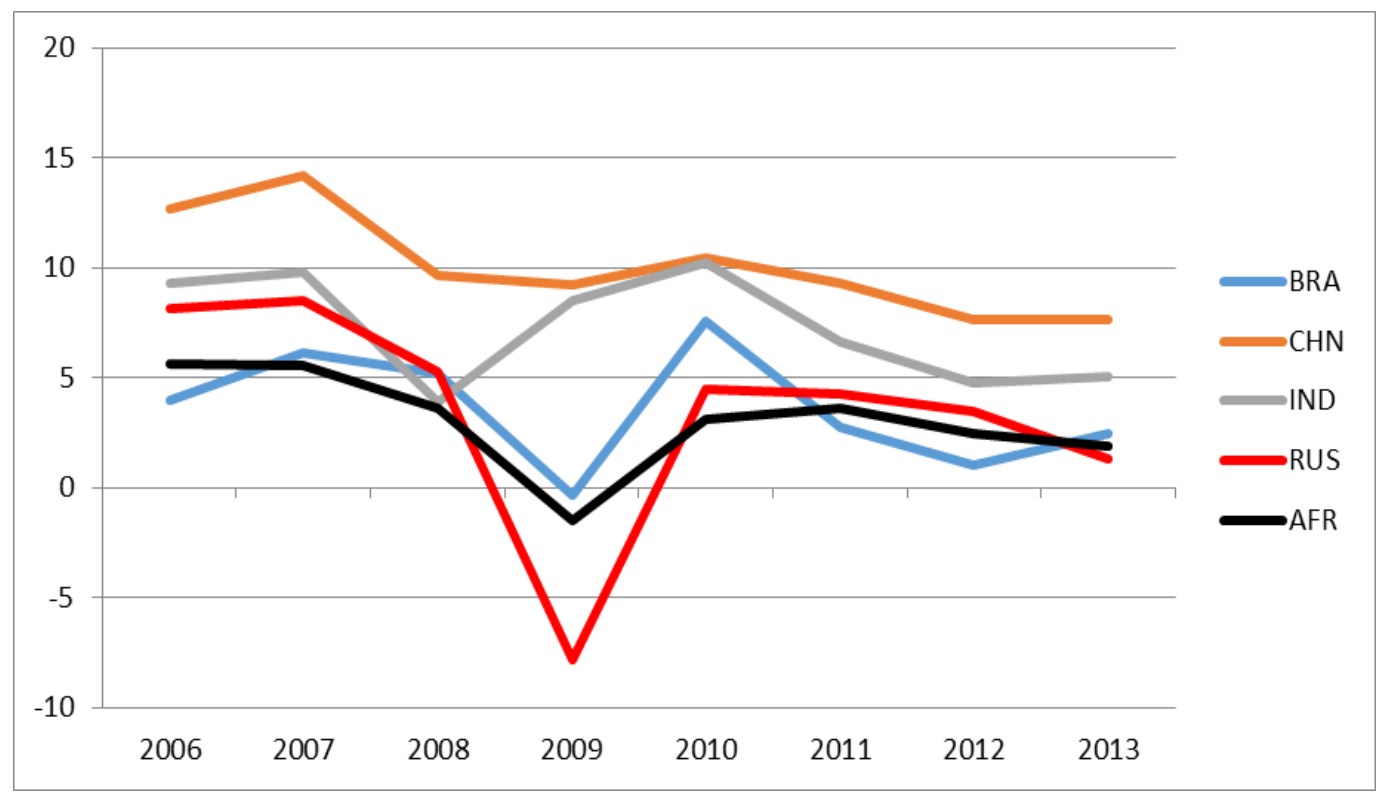

Gráfico 2: Taxa de crescimento do PIB dos BRICS - 2006 a 2013 - em \%

Fonte: dados da pesquisa

Em linhas gerais, verifica-se que os países do BRICS apresentaram elevados índices de crescimento do PIB nos primeiros anos subsequentes à formalização do grupo. Mesmo que essa taxa de crescimento venha diminuindo com o passar dos anos, é possível visualizar que a taxa de crescimento do PIB dos países analisados pode estar relacionada à criação de vínculo com os BRICS. Nesse caso, também é possível verificar que a China apresentou taxa de crescimento superior aos demais BRICS em todos os anos da série analisada.

Contudo, verifica-se que no ano de 2009 o Brasil, a África e, principalmente, a Rússia apresentaram decrescimento do PIB. Uma das razões que podem explicar esse fato refere-se à crise financeira ocorrida no ano anterior, o que pode ter afetado investimentos que exercem influência no PIB desses países.

Os resultados apresentados nessa análise são semelhantes aos obtidos por Santana et al (2014) no que se refere ao distanciamento da China em relação aos demais BRICS nas variáveis de cunho econômico. Contudo, ressalta-se que a análise proposta para este estudo visa a verificação de desenvolvimento sustentável dos BRICS como um bloco e não em termos individuais. Assim sendo, entende-se que, na medida em que todos os países que compõem o grupo apresentaram taxas de crescimento econômico na maior parte da série analisada e, guardando as proporções 
condizentes a cada país, existem sinais consideráveis da existência de sustentabilidade econômica para os BRICS. Esse resultado também se mostra consonante com Reis (2012) ao destacar que, economicamente, essa união favoreceu (ainda que parcialmente) a distribuição mais justa do peso econômico dos membros de instituições financeiras internacionais, além de favorecer os interesses de outros países em desenvolvimento.

\subsection{Desenvolvimento Social do BRICS}

Nesta sessão será analisado o aspecto social do BRICS, representado pela variável "expectativa de vida ao nascer". O gráfico 3 apresenta os dados referentes a expectativa de vida ao nascer para cada um dos componentes do BRICS.

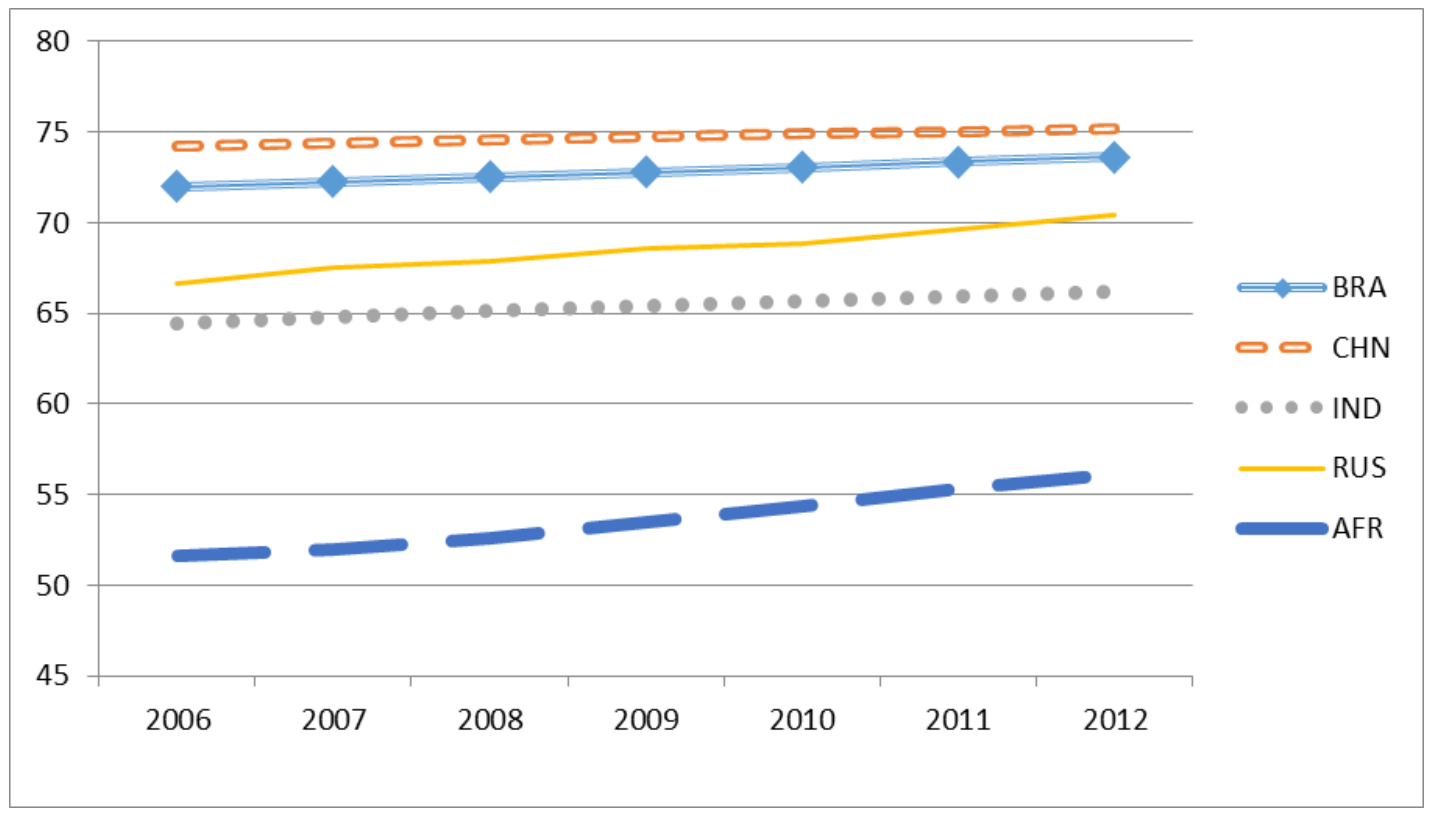

Gráfico 2: Desenvolvimento da expectativa de vida ao nascer dos BRICS - 2006 a 2012 - em anos Fonte: dados da pesquisa

Por meio da análise do gráfico é possível verificar a existência de uma disparidade entre a expectativa de vida na África do Sul em relação aos demais BRICS. É evidente que essa diferença não foi ocasionada pela participação do país no grupo, pelo contrário, é possível verificar uma elevação nesse indicador para o país africano, bem como para os demais países do grupo.

Também faz-se importante destacar o crescimento da expectativa de vida após o nascimento na Rússia e na África do Sul após a adesão ao BRICS. No período analisado, a população russa aumentou sua expectativa de vida em seis anos, ao 
passo que os sul-africanos obtiveram uma expectativa de vida quase que cinco anos maior.

O Brasil e a Índia também avançaram nesse indicador após inserção no BRICS, aumentando a expectativa de vida de seus cidadãos em 2 anos. A China, por sua vez, já apresentava um indicador considerado bom para esta variável. Resultados semelhantes foram observados na análise realizada por Zhen et al. (2009), que demonstravam uma evolução na sustentabilidade social na China.

Considerando esse indicador, observa-se que o BRICS representou um desenvolvimento social para os países que compõem o grupo. Entende-se que avanços nesse aspecto sinalizam que o grupo econômico corresponde aos anseios de desenvolvimento sustentável. Evidentemente, os avanços apresentados pelos países que compõem o BRICS não estão atrelados somente ao fato participação no mesmo. Várias são as ações tomadas pelos governantes desses países, como esforços para a otimização desses resultados. Contudo, entende-se que a cooperação efetivada a partir da criação do grupo pode ter resultado no desenvolvimento observado, em consonância com Reis (2012), que destaca os avanços na saúde e redução da pobreza proporcionados por esse acordo de cooperação.

\subsection{Desenvolvimento Ambiental dos BRICS}

Por fim, foram analisados os dados referentes ao desenvolvimento ambiental dos BRICS considerando-se o montante de milhões de toneladas de dióxido de carbono $\left(\mathrm{CO}_{2}\right)$ emitidos pelos países que compõem o grupo.

O gráfico 4 apresenta o volume de emissão de $\mathrm{CO}_{2}$ pelos BRICS no período compreendido entre os anos de 2006 a 2013. 


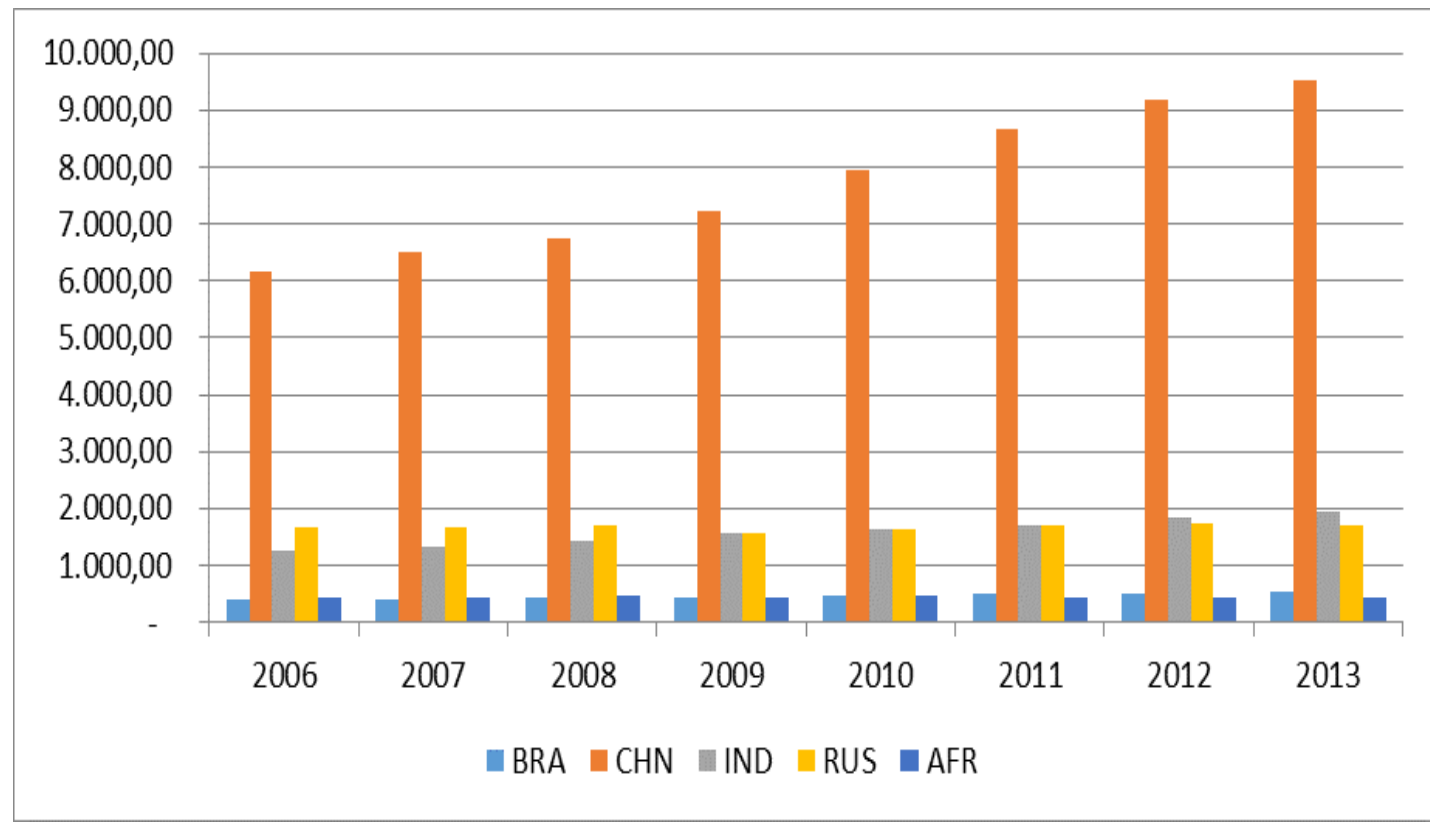

Gráfico 4: Volume de emissão de CO2 pelos BRICS - 2006 a 2013 - em milhões de toneladas Fonte: dados da pesquisa

Se nos aspectos relacionados ao desenvolvimento econômico e desenvolvimento social foram observados avanços pelos países emergentes após a adesão ao BRICS, o mesmo não pode ser dito no aspecto ambiental. Os dados analisados demonstram que após a formação dos BRICS os membros do grupo avançaram em sentido oposto ao de sustentabilidade no âmbito ambiental, com exceção da África do Sul, que reduziu o volume de toneladas de $\mathrm{CO}_{2}$ emitidas após a sua adesão ao grupo no ano de 2011. Cabe ressaltar que o volume de $\mathrm{CO}_{2}$ emitido por esse país poderia ser considerado razoavelmente baixo, antes mesmo da adesão ao BRICS.

Por outro lado, o crescimento econômico da China apresenta, quase que na mesma proporção, crescimento nos níveis de poluição. Esse resultado se mostra divergente do que foi obtido por Zhen et al. (2009), que apontavam um crescimento na sustentabilidade ambiental da China no período pós BRICS.

Percebe-se, assim, que se existe cooperação entre os países do BRICS no intuito de reduzir os poluentes, esses esforços de cooperação não estão sendo eficientes para o desenvolvimento sustentável do meio ambiente desses países. Tal aspecto pode ser confirmado analisando a situação da Índia e do Brasil, que aumentaram em, respectivamente, $55 \%$ e $41 \%$ os seus volumes de emissão de CO2. No caso do Brasil, esse resultado vai de encontro aos apresentados pelo IBGE (2008), demonstrando a ineficiência dos municípios brasileiros frente aos riscos ambientais.

\section{CONSIDERAÇÕES FINAIS}


Neste estudo objetivou-se realizar uma comparação entre as dimensões econômica, ambiental e social dos membros do BRICS, visando oferecer um panorama contextual do desenvolvimento sustentável nesses países.

Sendo assim, observou-se que, em relação ao desenvolvimento econômico e social, a composição do BRICS propiciou avanços advindos dessa cooperação. Os dados analisados na pesquisa revelaram que houve amplo desenvolvimento econômico da China durante a série estudada e que, mesmo presentando menor desenvolvimento se comparado ao chinês, o Brasil, a Rússia e a Índia também obtiveram avanços em seu desenvolvimento econômico. Não foi observado o mesmo desenvolvimento na África do Sul, mas é importante salientar que sua inclusão no BRICS ocorreu posteriormente aos demais países.

Em relação a sustentabilidade social, os dados analisados revelaram maior homogeneidade entre os países do BRICS, com exceção da África do Sul, cuja expectativa de vida se mostrou bastante díspar dos demais países. Este fato evidencia que a cooperação entre os países e a maior sinergia existente entre eles na busca de maior legitimidade internacional auxiliou-os no avanço de melhores condições sociais. Essa melhoria também pode ser inferida através do desenvolvimento econômico observado, mostrando que os aspectos econômicos e sociais tem conseguido avançar em equilíbrio.

O trabalho, entretanto, evidenciou que, em relação à sustentabilidade ambiental, não houve grandes avanços. Observou-se que ela não está sendo devidamente contemplada pelos planos de cooperação do BRICS. Um destaque evidenciado nesse estudo é que o desenvolvimento da produção chinesa foi acompanhado de uma maior emissão de $\mathrm{CO} 2$. O mesmo se evidenciou para o Brasil e a Índia.

Este ponto é fundamental para a compreensão das estratégias de atuação do BRICS. Percebe-se que tem sido dada uma ênfase muito grande ao desenvolvimento econômico e à inserção e representatividade destes países em instâncias internacionais, o que acaba colaborando para indicadores sociais também. Entretanto, tal ênfase não tem sido observada na questão ambiental. Na ansiedade de cooperarem na busca do desenvolvimento econômico, estes países acabam menosprezando a importância do desenvolvimento ambiental, colocando em dúvida se realmente estão promovendo um desenvolvimento sustentável.

Apesar disso, vale ressaltar que, apesar de recente, os BRICS apresentam evidências de que é possível evolução no processo de desenvolvimento sustentável através das sinergias surgidas nos processos de cooperação e parceria. Maior cuidado e esforço, porém, deveria ser empregado na promoção do desenvolvimento ambiental desses países emergentes. 
É importante também destacar que medidas para a promover a continuidade dos avanços no desenvolvimento econômico e social devem ser tomadas, mas procurando fazer maior interligação entre os diversos aspectos que compõem a sustentabilidade, ou seja, considerando o desenvolvimento equilibrado das vertentes econômicas, sociais e ambientais.

Nesse sentido, é fundamental que as políticas de cooperação do BRICS busquem estabelecer o desenvolvimento sustentável como um de seus objetivos. Se estes países desejam se posicionar estrategicamente como líderes mundiais, não há como o fazerem sem que atuem mais firmemente na construção de uma sociedade mais equilibrada e que não cometa os mesmos erros ambientais que foram cometidos no desenvolvimento de outros países, e que hoje se colocam perante a sociedade mundial como grandes desafios. Esse caminho só pode ser trilhado através de uma visão clara de desenvolvimento que inclua a faceta ambiental.

Finalmente, faz-se pertinente ressaltar como limitação desse estudo o número de varáveis analisadas. Dessa forma, sugere-se a realização de novos estudos futuros, que busquem contemplar outras variáveis, de forma a trazer uma perspectiva mais abrangente das dimensões da sustentabilidade analisadas nessa pesquisa. Além disso, devido ao caráter exploratório e descritivo dessa pesquisa, investigações em profundidade sobre essa temática também se mostram relevantes. Pesquisas que lancem mão de outros tipos de corte temporal também podem trazer novos e importantes resultados.

Por outro lado, defende-se que esse estudo alcançou seus objetivos, permitindo contextualizar algumas consequências das ações tomadas pelos BRICS no que tange desenvolvimento sustentável. Além disso, o estudo contribuí para as pesquisas acadêmicas, uma vez que inova ao efetuar uma análise sobre o desenvolvimento sustentável ocorrido no BRICS, analisando-o como um bloco único e não apenas os seus países individualmente. Esse estudo também contribui ao evidenciar os aspectos que têm sido priorizados por esse bloco de países em sua interação e cooperação na busca do desenvolvimento, que não se mostrou, nesse sentido, ainda sustentável. No que se refere a sua contribuição para sociedade, entende-se que o estudo contribui ao fornecer insights para tomada de decisão e reformulação de diretrizes por parte dos governantes, bem como para a geração de novos estudos, que tomem por base os resultados apresentados.

\section{REFERÊNCIAS}

ARMIJO, L. E. The BRICS countries (Brazil, Russia, India, and China) as analytical category: mirage or insight? Asian Perspective, v. 31, n. 4, 2007, pp. 7-42. 
BARBIERI, J. C.; VASCONCELOS, I. F. G. de; ANDREASSI, T.; VASCONCELOS, F. C. de. Inovação e Sustentabilidade: novos modelos e proposições. Revista de Administração de Empresas. São Paulo, v.50, n.2, abr/jun. 2010, p. 146-154.

BARONI, M. Ambiguidades e Deficiências do Conceito de Desenvolvimento Sustentável. Revista de Administração de Empresas. São Paulo, v.32, n.2, abr/jun.1992, p. 14-24.

BATISTA, I. H.; ALBUQUERQUE, C. C. de. Desenvolvimento Sustentável: novos rumos para a humanidade. Revista Eletrônica Aboré (Publicação da Escola Superior de Artes e Turismo). Edição 03/2007. Disponível em: $<$ http://www.revistas.uea.edu.br/old/abore/artigos/artigos_3/Ieda\%20Hortencio\%20B atista.pdf $>$. Acesso em novembro de 2014.

BEZERRA, M. C. Relatório do Grupo de trabalho do CONAMA sobre indicadores de cumprimento e aplicação de normas ambientais. Brasília, 2004. Disponível em: <http://www.mma.gov.br/port/conama/reuniao/dir602/ResultConsultAtores.doc.>. Acesso em novembro de 2014.

CARVALHO, H. M. Padrões de Sustentabilidade: uma medida para o desenvolvimento sustentável. In: D'INCAO, M.A.; SILVEIRA, I.M. (Org.) Amazônia e a crise da modernização. Belém: Museu Paraense Emílio Goeldi, 1994, p. 361-380.

CHENG, H. F.; GUTIERREZ, M.; MAHAJAN, A.; SHACHMUROVE, Y.; SHAHROKHI, M. A future global economy to be built by BRICs. Global Finance Journal, v.18, 2007, p. 143-156.

COMISSÃO MUNDIAL SOBRE MEIO AMBIENTE E DESENVOLVIMENTO (CMMAD). Nosso futuro comum. Rio de Janeiro: Fundação Getúlio Vargas, 1991.

COZETTI, N. Lixo: Marca incômoda da modernidade. Revista Ecologia e Desenvolvimento. Rio de Janeiro, ano 11, v. 96, 2001.

DANIEL, O. Definição de indicadores de sustentabilidade para sistemas agro florestais. 2000. 112 p. Tese (Doutorado em Ciência Florestal) - Universidade Federal de Viçosa, Viçosa, MG. 
DIEGUES, A. C. S. Desenvolvimento Sustentável ou Sociedades Sustentáveis: da crítica do modelo aos novos paradigmas. São Paulo em Perspectiva, v.6, n.1-2, jan/jun.1992, p. 22-29.

DOLGIKH, E.; KOKIN, S. The chinese economy and the other BRIC countries: the comparative analysis. International Conference on Management Science \& Engineering. 16. Setembro, 2009.

DRUMMOND, J. A. Desenvolvimento Sustentável: debates em torno de um conceito problemático. História, Ciências, Saúde- Manguinhos, v.5, n.3, nov/fev. 1999, p.755761.

FONSECA, J. R. G. BRICS: notas e questões. In: Mesa redonda: o Brasil, os BRICS e a agenda internacional / Apresentação do Embaixador José Vicente de Sá Pimentel. Brasília: FUNAG, 2012. 344 p.

GIL, A. C. Métodos e técnicas de pesquisa social. 6ed. São Paulo, Atlas: 2008.

GODARD, Olivier. O desenvolvimento sustentável: paisagem intelectual. In: CASTRO, E.; PINTON, F. (Orgs.). Faces do trópico úmido - conceitos e questões sobre desenvolvimento e meio ambiente. Belém: Cejup/UFPA-NAEA, 1997.

GONÇALVES, W. A Inserção do Brasil na América do Sul. OIKOS. Rio de Janeiro, v. 10, n. 2, 2011.

INSTITUTO BRASILEIRO DE GEOGRAFIA E ESTATÍSTICAS (IBGE). Perfil dos municípios brasileiros - 2008. Disponível em: <http://www.ibge.gov.br/home/estatistica/economia/perfilmunic/2008/>. Acesso em novembro de 2014.

LEE, Y. J.; HUANG, C. M. Sustainability index for Taipei. Environmental Impact Assessment Review, v. 27, n. 6, p. 505-521, 2007.

MEADOWS, D. Indicators and informations systems for sustainable development. The Sustainability Institute, $1998 . \quad$ Disponível em: <http://www.iisd.org/pdf/s_ind_2.pdf>. Acesso em novembro de 2014. 
MILANI, C. R. S. Aprendendo com a história: críticas à experiência da Cooperação Norte-Sul e atuais desafios à Cooperação Sul-Sul. Caderno CRH, v. 25, p. 211-231, 2012.

PEREIRA FILHO, S. R. E BAKKER F. I. Indicadores de Desenvolvimento Sustentável. Brasília, INEPAD/UNIBB: 2008.

PETTIGREW, A. M. Contextualist research and the study of organizational change processes. Disponível em: $<$ http://ifipwg82.org/sites/ifipwg82.org/files/Pettigrew.pdf >. Acesso em novembro de 2014.

REIS, M. E. F. BRICS: surgimento e evolução. In: Mesa redonda: o Brasil, os BRICS e a agenda internacional / Apresentação do Embaixador José Vicente de Sá Pimentel. Brasília: FUNAG, 2012. 344 p.

SANTANA, N. B.; REBELATTOA, D. A. do N.; PÉRICO, A. E.; MARIANO, E. B. Sustainable development in the BRICS countries: an efficiency analysis by data envelopment. International Journal of Sustainable Development \& World Ecology, v. 21, n.3, 2014.

SHI, C.; HUTCHINSON, S.; XU, S. Evaluation of coastal zone sustainability: an integrated approach applied in Shanghai Municipality and Chong Ming Island. Journal of Environmental Management, v. 71, n. 4, p. 335-344, 2004.

ULLRICH, D. R.; CARRION, R. D. S. M. A cooperação Sul-Sul como um novo padrão de relações internacionais? $\mathrm{O}$ caso do acordo de cooperação técnica entre UFRGS (Brasil) e Uni-CV (Cabo Verde). Revista de Geopolítica. Natal. v. 5, n. 1, jan./jun. 2014, p. 82-98, 2014.

VIZEU, F.; MENEGHETTI, F.K.; SEIFERT, R.E. Por uma crítica ao conceito de desenvolvimento sustentável. Cad. EBAPE.BR, v. 10, n.3, art. 6, set. 2012.

WALLAVER, J. P. ABC do meio ambiente, fauna brasileira. Brasília: Editora IBAMA, 2000.

ZHEN, L.; CAOB, S.; WEIA, Y.; DILLYD, O.; LIUA, X.; LIA, F.; KOENIGE, H.; TSCHERNINGE, K.; HELMINGE, K. Comparison of sustainability issues in two 
MOREL, A. P. S.; et al. Desenvolvimento Sustentável: Uma Análise Contextual...

sensitive areas of China. Environmental Science \& Policy, v. 12, n. 8, p. 1153-1167, 2009. 